\title{
ANALISIS KINERJA HEATING VENTILATING AIR CONDITIONING BUILDING AUTOMATION SYSTEM PADA LABORATORIUM LISTRIK
}

\author{
Muhammad Agung, Fikri Dwi Nugroho, Murie Dwiyaniti, Anicetus Damar Aji
}

${ }^{1}$ Teknik Otomasi Listrik Industri, Jurusan Teknik Elektro, Politeknik Negeri Jakarta, Jl. Prof. DR. G.A. Siwabessy, Kukusan, Kecamatan Beji, Kota Depok, 16424, Indonesia

E-mail: muhammad.agung.te17@mhsw.pnj.ac.id,murie.dwiyaniti@elektro,pnj,ac,id

\begin{abstract}
$B A S$ is used to optimize system control and performance of HVAC system equipment. This study discusses the performance of miniature BAS for HVAC systems, especially AHU systems in electrical laboratories that use DDC and HMI. The performance of the AHU system was tested on the security system, manualautomatic-interference mode, Modbus to BACnet communication, trend, and sensor performance. As a result, the security system succeeded in limiting the access rights of each user and activating auto log-off after 10 minutes. In manual mode, the digital output is successfully operated via the override switch within 1 second with the input status displayed on the HMI, the motorized damper has a position error of $1.57 \%$ and a position accuracy of $98.43 \%$, and a deviation of $0.29 \%$ on the AHU fan's VSD AO. In automatic mode, the system successfully operates in sequence system according to the schedule in the ASHRAE Guideline 13-2015. In the fault mode, the disturbance is detected, displays an alarm message, and activates the safety shutdown. Then, the Modbus to BACnet communication was successfully carried out on the system and the trend was successfully displayed and saved. XML format and the sensor performance were in accordance with the sensor datasheet.
\end{abstract}

Keywords: $A H U, B A S, D D C . H M I, H V A C$

\section{ABSTRAK}

BAS digunakan untuk mengoptimalkan pengendalian sistem dan kinerja dari peralatan sistem HVAC yang digunakan untuk pengkondisian udara pada suatu gedung. Dalam penelitian ini dibahas kinerja miniatur BAS untuk sistem HVAC khususnya sistem AHU pada laboratorium listrik yang menggunakan DDC sebagai controller serta HMI TPC-70. Kinerja sistem AHU diuji pada security system, mode manual, mode otomatis, mode gangguan, komunikasi Modbus ke BACnet dengan gateway, monitoring menggunakan trend, dan kinerja sensor dengan menggunakan BAS. Hasilnya, security system berhasil membatasi hak akses tiap user dan mengaktifkan auto log off setelah 10 menit. Pada mode manual, output digital berhasil dioperasikan melalui override switch dalam waktu 1 detik dengan status input yang ditampilkan pada HMI, analog motorized damper mengalami error posisi sebesar 1,57\% dan akurasi posisi sebesar 98,43\%, dan terjadi deviasi sebesar 0,29\% pada output analog VSD fan AHU. Pada mode otomatis, sistem berhasil beroperasi dengan schedule sesuai sequence system pada pedoman ASHRAE Guideline 13-2015. Pada mode gangguan, gangguan berhasil dideteksi, menampilkan message alarm, dan mengaktifkan safety shutdown. Kemudian, komunikasi Modbus ke BACnet berhasil dilakukan pada sistem dan trend berhasil ditampilkan dan disimpan dalam format .XML serta kinerja sensor sesuai dengan datasheet sensor.

Kata kunci: AHU, BAS, DDC. HMI, HVAC

ELECTRICES VOL 3 NO 22021 


\section{PENDAHULUAN}

BAS mengoptimalkan pengendalian sistem dan performansi dari peralatan HVAC (Heating, Ventilating, and Air Conditioning) pada suatu gedung untuk meningkatkan kenyamanan pemilik pada pengkondisian udara, optimalisasi energi yang digunakan, dan menyediakan off-site kontrol dan monitoring gedung [1], [2].

Saat ini, Politeknik Negeri Jakarta khususnya di Laboratorium Listrik telah memiliki miniatur BAS untuk sistem HVAC yang terdiri dari sistem chiller, sistem Air Handling Unit (AHU), dan sistem Fan Coil Unit (FCU). Pengendali BAS menggunakan Direct Digital Control (DDC) yang diprogram melalui software PS4000.

Direct Digital Control (DDC) merupakan sebuah bentuk close loop control. Kata "Direct" berarti mikroprosessor pada DDC secara langsung mengontrol loop tersebut dan kata "Digital" yang berarti kontrol tersebut dilakukan oleh komponen digital pada mikroprosessor [3]. DDC biasanya disebut automation station yang dapat menjalankan fungsi supervisory serta pengontrolan [4]. DDC controller dapat melakukan kontrol kompleks, memiliki lebih banyak memori serta dapat mengaktifkan alarm dan dapat menghasilkan data trend [5], [6]. Kontrol aktuator dengan DDC juga lebih akurat karena terdapat Propotional Integral Derivative (PID) Control [6]. DDC juga dapat berkomunikasi antar controller dan komputer operator atau HMI melalui sambungan router. DDC controller merupakan controller yang paling hemat biaya untuk sistem HVAC [7].

PS4000 adalah sistem perencanaan yang dikembangkan oleh Kieback\&Peter. Digunakan untuk pembuatan project dengan bantuan komputer untuk plant HVAC [8]. Automation station seri DDC4000 serta perangkat pihak ketiga dapat dimasukkan dalam project.

Seluruh sistem HVAC dihubungkan sedemikian rupa untuk menghasilkan miniatur BAS yang dapat digunakan sebagai media praktek mahasiswa. Namun, kinerja dari masingmasing peralatan pada miniatur BAS tersebut belum diketahui. Kinerja dari masing-masing peralatan pada miniatur BAS untuk sistem HVAC dapat diketahui melalui rancang bangun program pada Direct Digital Control (DDC) dengan PS4000 sesuai dengan sistem kerja, pembuatan program komunikasi Modbus ke BACnet pada MBS Gateway, dan pembuatan program HMI pada TPC 70 menggunakan Service Tool. Sehingga tujuan dari penelitian ini adalah melakukan analisis terhadap kinerja setiap peralatan BAS agar dapat digunakan untuk praktek mahasiswa secara baik dan benar. Kinerja AHU diuji pada security system, mode manual, mode otomatis, mode gangguan, komunikasi Modbus ke BACnet dengan gateway, monitoring menggunakan trend, dan kinerja sensor dengan menggunakan BAS [9],[10]. Semua kinerja tersebut akan menjadi acuan mahasiswa dalam pembelajaran praktik.

\section{METODE PENELITIAN}

Metode penelitian yang digunakan adalah rancang bangun dan eksperimen. Tahapan penelitian yang dilakukan adalah.

1. Merancang sistem sesuai arsitektur BAS, mendata spesifikasi peralatan, dan menggambar wiring diagram sistem.

2. Membuat deskripsi kerja dan program DDC menggunakan PS4000, program HMI menggunakan Service Tool, program MBS Gateway, dan konfigurasi VSD.

3. Menguji kinerja sistem AHU pada security system, mode manual, mode otomatis, mode gangguan, komunikasi Modbus ke BACnet dengan gateway, monitoring menggunakan trend, dan kinerja sensor dengan menggunakan BAS.

4. Analisa data yang didapat dengan membandingkan kinerja sistem dengan pedoman atau standar yang ada.

Rancangan miniatur BAS untuk sistem HVAC terlihat pada Gambar 1.
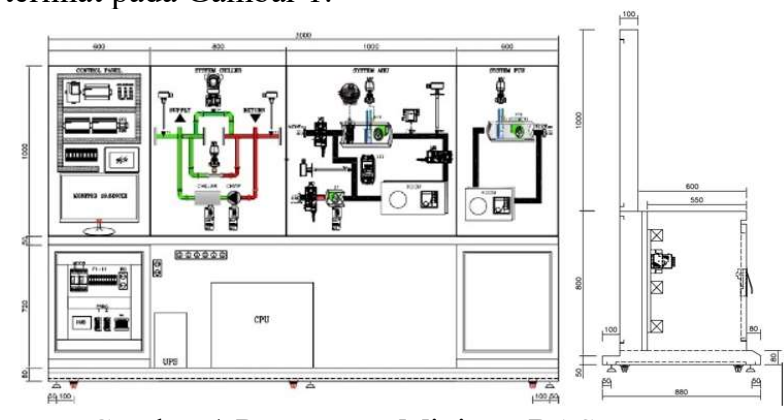

Gambar 1 Rancangan Miniatur BAS

Miniatur sistem BAS untuk sistem HVAC memiliki 5 bagian utama, yaitu power panel., control panel, sistem chiller, sistem AHU, dan sistem FCU. Peralatan miniature BAS terlihat pada Gambar 2. 


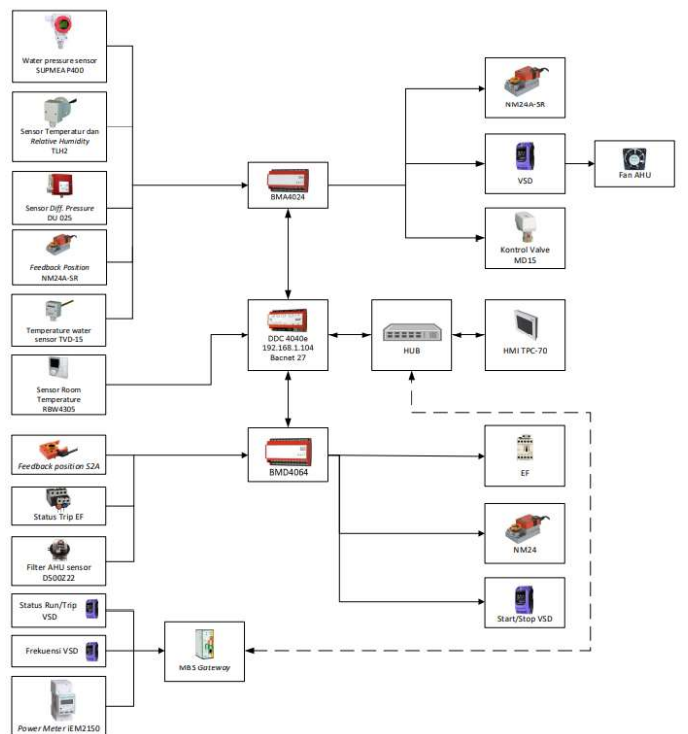

Gambar 2 Peralatan miniature BAS

Semua input berupa sensor temperatur, humidity dan kelembapan serta output berupa kontrol valve, motorized damper, dan VSD pada sistem terhubung dengan DDC 4040e melalui switch cabinet bus BMA4024 dan DDC BMD4064 melalui Controller Area Network (CAN) 1. Pada CAN 2 DDC terhubung RBW4305 sebagai fieldbus untuk room temperatur sensor. HMI, MBS Gateway, dan PC terhubung melalui hub untuk komunikasi dengan DDC 4040e.

Deskripsi kerja miniature BAS ini terdiri dari mode manual, mode otomatis, mode gangguan.

Pada mode manual, setiap peralatan dioperasikan secara manual melalui test program start-stop. Pada mode kerja otomatis, peralatan sistem beroperasi secara berurutan (sequence) sesuai deskripsi kerja yang ditentukan. Semua data yang terjadi pada saat sistem bekerja direkam oleh DDC dan ditampilkan pada HMI. Sedangkan pada mode kerja gangguan dibagi dua yaitu alarm mayor dan minor. Alarm mayor adalah mode kerja gangguan yang mengaktifkan alarm apabila terjadi trip pada sistem. Alarm mayor sistem AHU akan aktif apabila terjadi trip pada fan AHU dan EF. Sedangkan, alarm minor adalah mode kerja gangguan yang terjadi apabila terjadi kenaikan atau penurunan temperatur dan tekanan dari limit yang diinginkan. Ketika sistem sudah masuk ke mode kerja gangguan maka DDC akan mengirimkan data ke HMI-TPC70 tentang gangguan yang terjadi dan akan menampilkan alarm. Sistem baru bisa kembali normal jika gangguan sudah direset.

\section{HASIL DAN PEMBAHASAN}

A. Pengujian security system sistem AHU

Security system pada sistem AHU terdiri dari program code level (manajemen pengguna) yang digunakan untuk menspesifikasikan hak akses user. Pengujian ini bertujuan untuk mengetahui fungsi security system sesuai hak akses yang diberikan pada suatu program input dan mengatur waktu auto log-off pada sistem sesuai ASHRAE Guideline 13-2015 mengenai Specifying Building Automation Systems.

Pengujian security system dilakukan dengan login dan tanpa login user serta auto logoff.

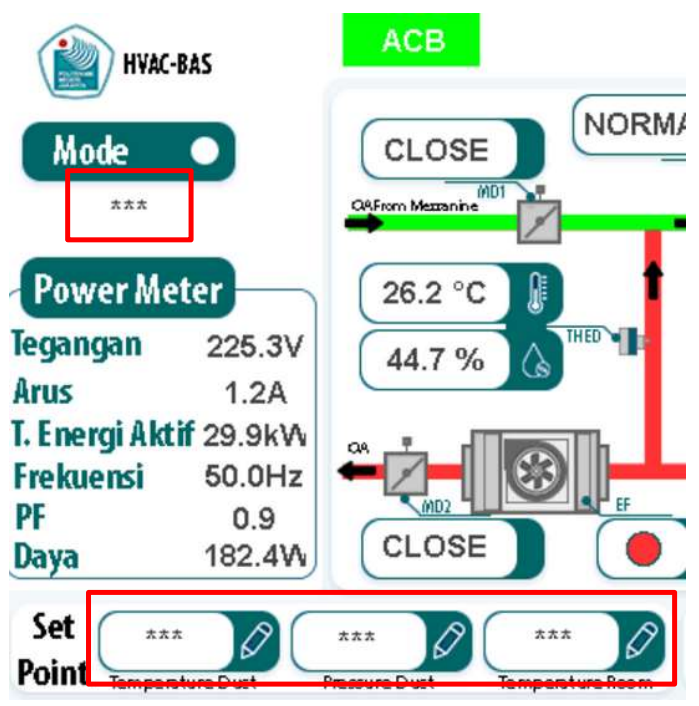

Gambar 3. Tampilan HMI tanpa Login User

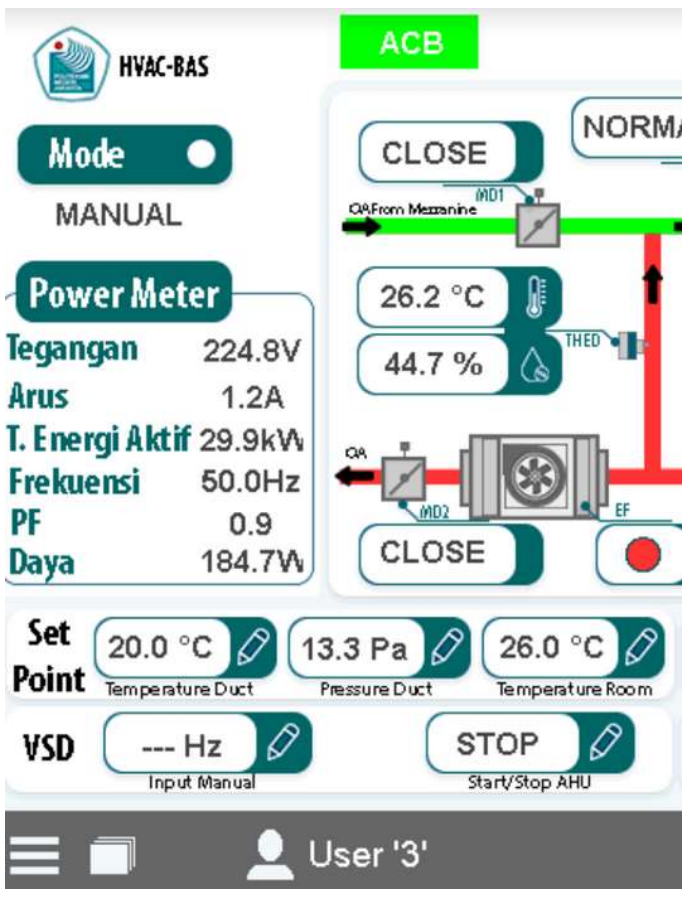

Gambar 4. Tampilan HMI dengan Login User 
Pada Gambar 3 terlihat tampilan tanpa login user (logged off). Ketika user tidak login (mode tamu) saat masuk plant, override switch yang digunakan untuk mengatur mode operasi sistem AHU tidak dapat dioperasikan dan menampilkan format *** pada plant. Jika user melakukan login, tampilan layer HMI terlihat pada Gambar 4 , seluruh override switch yang digunakan untuk mengatur mode operasi sistem AHU dapat diakses dan ditampilkan dalam format sesuai program yang dibuat.

Hasil pengujian ini sesuai dengan pedoman ASHRAE Guideline 13-2015 mengenai Specifying Building Automation Systems pada bagian security systems yang menjelaskan keamanan sistem harus dapat dipilih untuk setiap user. Program pada sistem harus dapat membatasi fungsi yang dapat diakses oleh user untuk melihat dan/atau mengubah setiap aplikasi sistem, editor, dan objek. Kesesuaian ini dapat dilihat pada plant sistem AHU ketika hak akses pengoperasian dibatasi hanya untuk User 3.

Pada pengujian auto log-off ketika sistem tidak lagi mendeteksi input atau sentuhan pada HMI TPC-70 maka user akan otomatis logoff dari sistem sesuai waktu yang ditentukan user. Hal ini sesuai dengan pedoman ASHRAE Guideline 13-2015 mengenai Specifying Building Automation Systems pada bagian security systems yang menjelaskan keamanan sistem mengatur user agar secara otomatis logoff dari sistem jika tidak ada aktivitas input yang terdeteksi. Jangka waktu auto log-off ini dapat diatur oleh user.

\section{B. Pengujian Mode Manual Sistem AHU}

Tujuan dari pengujian ini, mengetahui kinerja setiap peralatan I/O. Pengujian dilakukan melalui HMI TPC70 dengan mengoperasikan override switch mode manual input digital dan input analog yang telah terhubung pada modul $\mathrm{I} / \mathrm{O}$.

Tabel 1 merupakan hasil respons output digital ketika mode manual menyesuaikan perintah input DDC dari override switch dengan waktu respons tiap perangkat terhadap perintah selama \pm 1 detik. Waktu respons terhadap perintah input DDC memenuhi standar performa sistem BAS berdasarkan pedoman ASHRAE Guideline 13-2015 yang menjelaskan mengenai output digital akan bereaksi setelah diberi perintah dari controller dalam 2 detik. Selain itu, respons output digital pada Tabel 1 juga mempengaruhi kondisi tampilan status pada HMI TPC-70. Pada Tabel 2, output digital pada plant sistem AHU telah merespons sesuai dengan waktu respons standar performa BAS dan menampilkan status yang sesuai dengan respons output digital yang dioperasikan pada HMI TPC70.

Tabel 1 Pengujian Output Digital Mode Manual

\begin{tabular}{|c|c|c|c|}
\hline \multirow{2}{*}{ Pengujian } & \multirow{2}{*}{$\begin{array}{l}\text { Respons } \\
\text { Time (s) }\end{array}$} & \multicolumn{2}{|c|}{ Kondisi } \\
\hline & & Status HMI & Output \\
\hline Lamp OFF & 1 & & \\
\hline Lamp ON & 1 & & \\
\hline Close MD1 & 1 & CLOSE & \\
\hline Open MD1 & 1 & OPEN & \\
\hline Close MD2 & 1 & & \\
\hline Open MD2 & 1 & & \\
\hline Stop AHU & 1 & (1) & \\
\hline Start AHU & 1 & 0 & \\
\hline Stop EF & 1 & (ே) & y \\
\hline Start EF & 1 & (0) & 1 \\
\hline
\end{tabular}

Pada Tabel 2 dapat dilihat persentase error dan akurasi posisi dari tiap posisi analog motorized damper. Pada perhitungan didapatkan persentase error rata-rata sebesar 1,57\% dan akurasi posisi rata-rata sebesar $98,43 \%$. Berdasarkan hal tersebut, akurasi posisi pada hasil pengujian masih memenuhi standar akurasi posisi pada datasheet analog motorized damper NM24A-SR sebesar $\pm 5 \%$.

Tabel 2 Pengujian Motorized Damper MD3

\begin{tabular}{|c|c|c|c|c|}
\hline $\begin{array}{l}\text { Posisi } \\
(\%)\end{array}$ & $\begin{array}{c}\text { Posisi } \\
\text { Feedbac } \\
\text { k (\%) }\end{array}$ & Error & $\begin{array}{l}\text { Persentase } \\
\text { Error }(\%)\end{array}$ & $\begin{array}{l}\text { Akur } \\
\text { asi } \\
\text { Posisi } \\
(\%)\end{array}$ \\
\hline 10 & 9,50 & 0,5 & 5,00 & 95,00 \\
\hline 20 & 19,80 & 0,2 & 1,00 & 99,00 \\
\hline 30 & 29,50 & 0,5 & 1,67 & 98,33 \\
\hline 40 & 39,30 & 0,7 & 1,75 & 98,25 \\
\hline 50 & 49,50 & 0,5 & 1,00 & 99,00 \\
\hline 60 & 61,30 & 1,3 & 2,17 & 97,83 \\
\hline 70 & 69,40 & 0,6 & 0,86 & 99,14 \\
\hline 80 & 79,30 & 0,7 & 0,88 & 99,13 \\
\hline 90 & 89,20 & 0,8 & 0,89 & 99,11 \\
\hline 100 & 100,50 & 0,5 & 0,50 & 99,50 \\
\hline \multicolumn{3}{|c|}{ Error Rata-Rata (\%) } & 1,57 & \\
\hline \multicolumn{3}{|c|}{$\begin{array}{c}\text { Akurasi Posisi Rata-Rata } \\
(\%)\end{array}$} & & 98,43 \\
\hline
\end{tabular}


Pada Tabel 3, input manual ke VSD berhasil masuk dan menggerakan fan sesuai dengan input frekuensi yang masuk ke VSD. Namun, terdapat perbedaan frekuensi yang masuk ke VSD dengan input frekuensi yang dimasukkan oleh user. Hal ini terjadi karena adanya deviasi pada output analog yang dikeluarkan oleh DDC sehingga terjadi error antara tegangan output yang diharapkan dengan yang dikeluarkan oleh DDC. Deviasi ini terjadi karena adanya signal loss pada sinyal input 0$10 \mathrm{~V}$ dari DDC ke VSD yang disebabkan oleh gangguan listrik dari peralatan seperti relay, motor, atau power supply.

Tabel 3 Pengujian VSD Fan AHU

\begin{tabular}{ccc}
\hline $\begin{array}{c}\text { Frekuensi } \\
\text { VSD (Hz) }\end{array}$ & $\begin{array}{c}\text { Perhitungan } \\
\text { Tegangan } \\
\text { Output (V) }\end{array}$ & $\begin{array}{c}\text { Pengukuran } \\
\text { Tegangan } \\
\text { Output (V) }\end{array}$ \\
\hline 10 & 2 & 2,028 \\
20 & 4 & 4,025 \\
30 & 6 & 6,04 \\
40 & 8 & 8,02 \\
50 & 10 & 10 \\
\hline Error Rata-rata $(\%)$ & 0,29 \\
\hline
\end{tabular}

C. Pengujian Mode Otomatis Sistem AHU

Tujuan dari pengujian ini, mengetahui kinerja dari program DDC mode otomatis dan memastikan sequence program mode otomatis berfungsi dengan baik berdasarkan schedule yang ditentukan $u$ ser.

Pengujian dilakukan pada HMI TPC70 dengan mengoperasikan switch mode otomatis pada sistem AHU dan mengamati HMI dan respons output sesuai dengan sequence system.

\begin{tabular}{|c|c|c|c|c|c|c|c|}
\hline$\square$ & \multicolumn{7}{|c|}{ < Schedule Sistem } \\
\hline SYSTEM CHILLER & \multicolumn{7}{|c|}{ Weekly schedule } \\
\hline SYSTEM AHU & Mo & Tu & We & Th & $\mathrm{Fr}$ & $\mathrm{Sa}$ & su \\
\hline \multirow[t]{3}{*}{ SYSTEM FCU } & \multicolumn{3}{|c|}{ from 00:00 o'clock } & \multicolumn{3}{|l|}{ Off } & Standard \\
\hline & \multicolumn{3}{|c|}{ from 11:50 o'clock } & On & & \multicolumn{2}{|r|}{ 亩 } \\
\hline & \multicolumn{3}{|c|}{ from $11: 55$ o'clock } & Off & & \multicolumn{2}{|r|}{$>$ 面 } \\
\hline $\begin{array}{c}\text { User '3' } \\
6 / 07 / 21 \text {-11:44 }\end{array}$ & & & & & & & \\
\hline$\equiv \square \Delta 2$ & \multicolumn{7}{|c|}{ (2+ 世 } \\
\hline
\end{tabular}

Gambar 2 Schedule Sistem AHU

Pada Gambar 5, schedule sistem mode otomatis akan ON pada pukul 11.50 dan akan OFF pada pukul 11.55. Aktifnya schedule pada mode otomatis ditunjukkan pada timechart Gambar 6

Proses matinya seluruh device sekitar 3 menit dari 11.55-11.58. Berdasarkan hal tersebut, schedule sistem dan sequence program mode otomatis plant sistem AHU telah berhasil diimplementasikan pada kondisi otomatis sistem
AHU. Mengacu pada ASHRAE Guideline 132015 mengenai sequence system yang menyatakan sistem harus dapat beroperasi sesuai sequence berdasarkan schedule yang ditentukan oleh user.

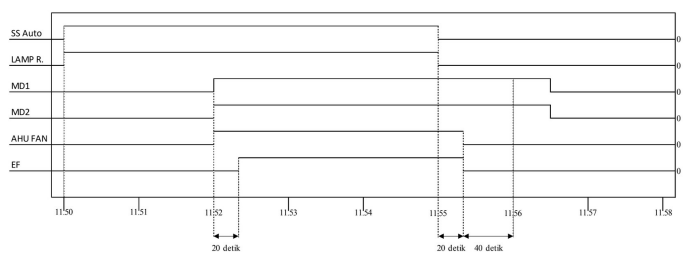

Gambar 3 Timechart Mode Otomatis Sistem AHU

Sequence system pada timechart Gambar 6 mengacu pada ASHRAE Guideline 13-2015 mengenai safety operation pada sistem AHU untuk memastikan seluruh peralatan aktif berdasarkan sequence system setelah udara pada ducting dideteksi pada sistem

\section{Pengujian Mode Gangguan Sistem AHU}

Pengujian program mode gangguan sistem AHU dilakukan dengan mengaktifkan alarm minor dan mayor ketika sistem sedang beroperasi. Tujuan dari pengujian ini, mengetahui kinerja dari program DDC mode gangguan dan memastikan semua alarm minor dan mayor berfungsi dengan baik.

Ketika terjadi gangguan, status indikator pada HMI TPC70 berubah menjadi merah dan muncul message pada HMI TPC70 seperti pada Gambar 7.

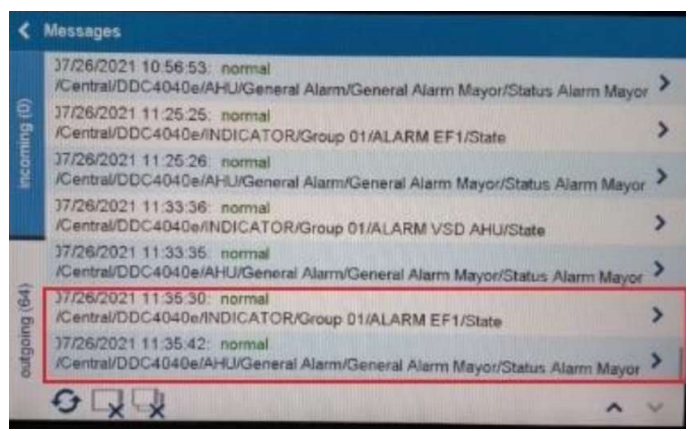

Gambar 7 tampilan message alarm pada HMI

Ketika gangguan berupa trip terjadi, fan akan berhenti berputar dan menampilkan status stop dan trip $O N$ pada HMI TPC-70. Kemudian, muncul simbol $\mathbb{1}$ pada HMI TPC-70 \pm 1 detik. Klik simbol tersebut untuk menampilkan message alarm malfunction yang terjadi pada incoming. Message alarm untuk trip VSD menampilkan dua message alarm dengan jarak waktu yang berdekatan yaitu alarm mayor dan alarm VSD AHU. Kondisi ini memenuhi pedoman ASHRAE Guideline 13-2015, alarm 
respons time pada sistem BAS akan mengirim alarm sistem setelah gangguan terdeteksi \pm 1 menit. Selain itu, alarm juga akan menampilkan beberapa message alarm dengan interval 1-5 detik sesuai dengan kondisi dan area terjadinya gangguan.

Setelah trip diatasi dan direset, fan akan berputar kembali dan menampilkan status run dan trip $O F F$ pada HMI TPC-70. Kemudian, muncul simbol ia pada HMI TPC-70. Klik simbol tersebut untuk menampilkan message alarm normal.

\section{E. Pengujian Komunikasi Modbus ke BACnet pada Sistem AHU}

Pengujian komunikasi Modbus ke BACnet pada sistem AHU dilakukan untuk memastikan komunikasi modbus ke BACnet melalui MBS Gateway telah berhasil dan data BACnet dapat dibaca oleh program DDC. Pengujian ini dilakukan dengan membandingkan data pembacaan modbus ke BACnet yang ada pada MBS Gateway dengan data yang ditampilkan pada power meter HMI TPC70 dan IEM215.

Tabel 3 Tampilan data pada power meter IEM215 dan HMI TPC-70

\begin{tabular}{|c|c|c|}
\hline Parameter & $\begin{array}{c}\text { Tampilan } \\
\text { Power Meter }\end{array}$ & $\begin{array}{c}\text { Tampilan Power } \\
\text { Meter pada HMI } \\
\text { TPC-70 }\end{array}$ \\
\hline Tegangan & $228.7=$ & \\
\hline Arus & & \\
\hline $\begin{array}{l}\text { T. Energi } \\
\text { Aktif }\end{array}$ & & $\begin{array}{|lc|}\text { Tegangan } & 228.5 \mathrm{~V} \\
\text { Arus } & 1.2 \mathrm{~A}\end{array}$ \\
\hline Frekuensi & & $\begin{array}{|lc|}\text { Frekuensi } & 50.0 \mathrm{~Hz} \\
\mathrm{PF} & 0.8 \\
\text { Daya } & 145.1 \mathrm{~W}\end{array}$ \\
\hline PF & & \\
\hline Daya & & \\
\hline
\end{tabular}

Berdasarkan Tabel 3, terdapat perbedaan data pada tampilan power meter iEM2150 dengan HMI TPC-70. Hal ini terjadi karena hasil gambar tampilan data power meter yang ditangkap kamera tidak dapat menyesuaikan kecepatan timestamp data power meter sebesar 1 detik perdata pengukuran.

\section{F. Pengujian Trend Sistem AHU}

Tujuan dari pengujian ini, memastikan pembacaan sensor dan power meter dapat ditampilkan dalam bentuk trend serta dapat disimpan dalam bentuk file .XML melalui HMI TPC70 yang mengakses data dari DDC.

Pengujian trend data pada sistem AHU dilakukan dengan menampilkan trend pada HMI
TPC70 melalui plant trend customer level. Kemudian, trend yang telah disimpan oleh DDC akan diambil dan disimpan pada PC client atau laptop dalam bentuk file .XML.

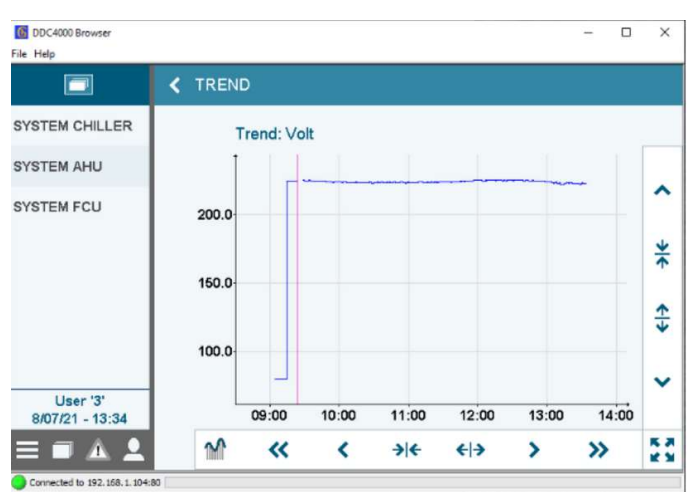

Gambar 8 Trend Tegangan

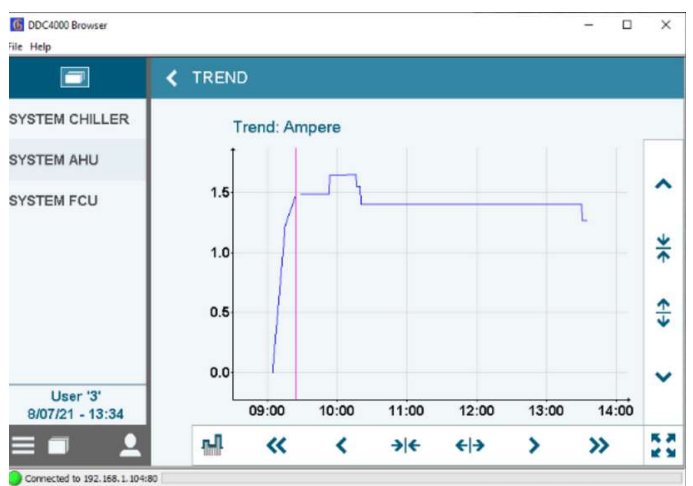

Gambar 9 Trend Arus

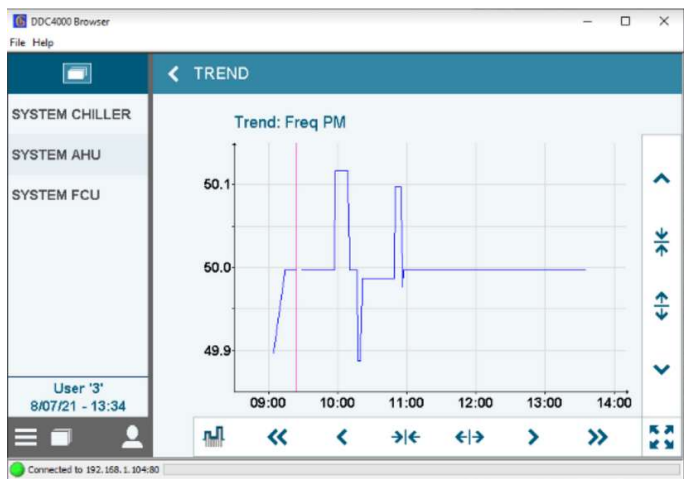

Gambar 40 Trend Frekuensi

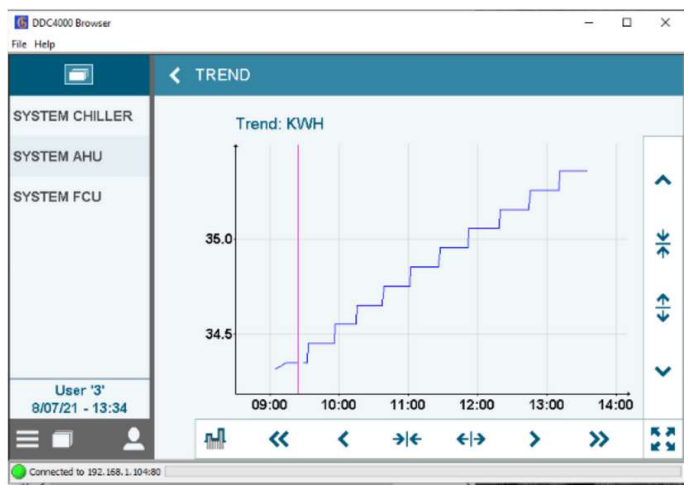

Gambar 51 Trend Total Energi Aktif 


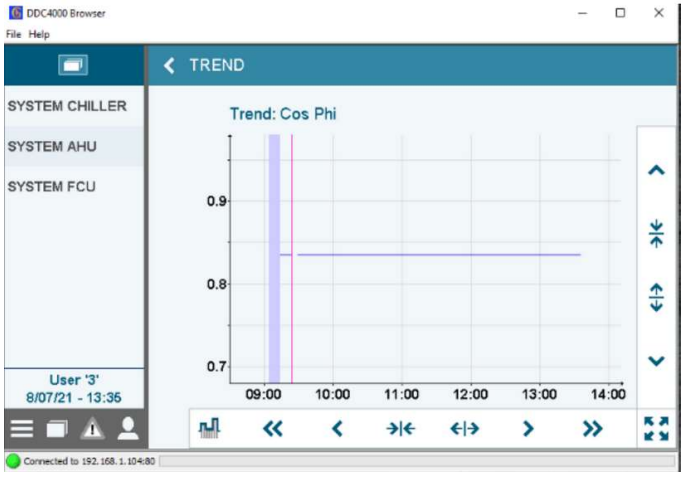

Gambar 12 Trend Cos Phi

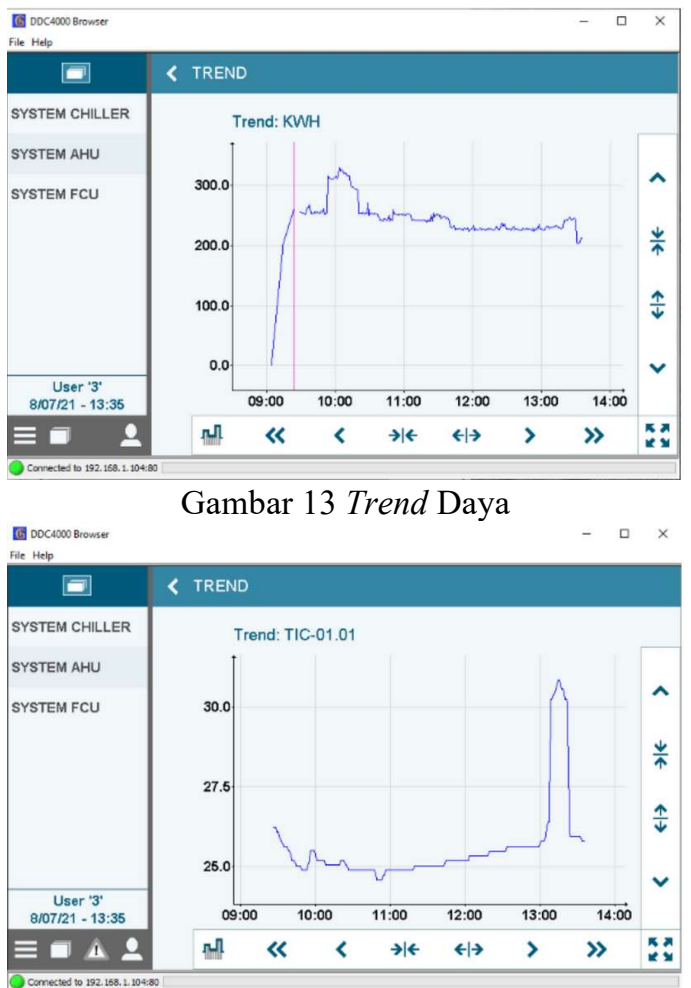

Gambar 14 Trend Temperature Duct SupplyTIC_01.01 pada Sistem AHU

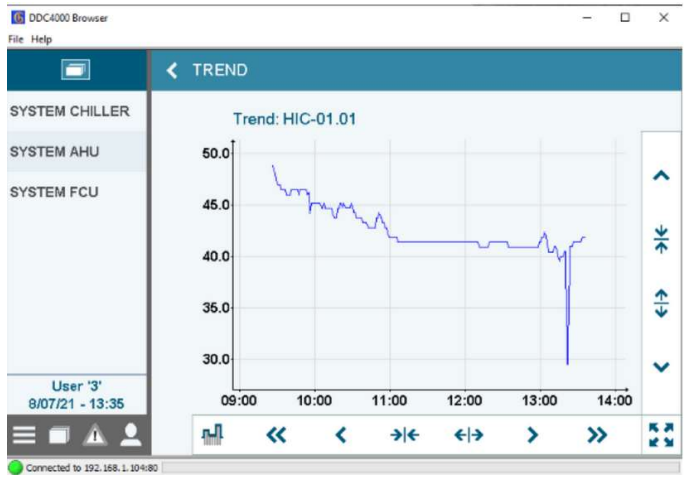

Gambar 15 Trend Humidity Duct Supply HIC_01.01 pada Sistem AHU

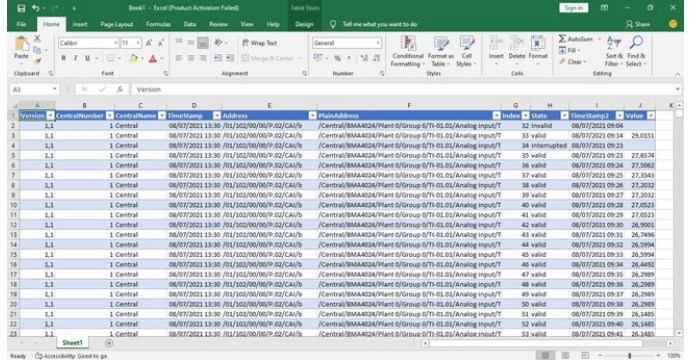

Gambar 16 Tampilan File Data Trend .XML

Trend pada Gambar 8-13 menampilkan trend data dari power meter yang diambil per 60 detik. Pada trend dapat dilihat garis vertikal berwarna ungu yang memotong grafik. Hal ini terjadi karena adanya kegagalan pada MBS gateway sehingga loss of communication terjadi saat upload program dari PS4000 ke DDC4040e pada pukul 09.28. Setelah program DDC terupload, tampilan grafik normal kembali dan merekam data pembacaan tegangan per 60 detik. Kondisi ini dijelaskan pada ASHRAE Guideline 13-2015 mengenai limitation pada Gateway yang menjelaskan kegagalan komunikasi pada gateway akan menyebabkan loss of communication antara gateway dengan semua device yang terhubung.

Gambar 14-15 merupakan trend sensor yang digunakan pada plant sistem AHU. Trend sensor ini diaktifkan untuk memonitoring dan mendata kondisi pembacaan sensor pada plant sistem AHU agar kondisi alarm minor dapat didata oleh user. Trend yang ditampilkan pada plant sistem AHU juga telah sesuai dengan pedoman ASHRAE Guideline 13-2015 mengenai standar $\mathrm{X}-\mathrm{Y}$ trend plot yang menjelaskan tampilan trend dapat diatur pada posisi $\mathrm{X} / \mathrm{Y}$ sesuai kebutuhan user dan dapat dilihat berdasarkan periode waktu, hari, dan bulan.

Trend log pada plant sistem AHU juga dapat disimpan atau di-export dalam format standar seperti .XML pada Gambar 16.

\section{KESIMPULAN}

1. Security system sistem AHU berhasil membatasi hak akses tiap user dan mengaktifkan auto log-off setelah 10 menit user yang login tidak memberikan input pada sistem.

2. Mode manual pada plant sistem AHU berhasil digunakan untuk mengoperasikan seluruh device sesuai kondisi manual tiap device. Output digital berhasil dioperasikan melalui override switch dalam waktu 1 detik dengan status input yang terdeteksi dan ditampilkan pada HMI, analog motorized damper mengalami error posisi sebesar $1,57 \%$ dan akurasi posisi sebesar $98,43 \%$, 
dan terjadi deviasi sebesar 0,29\% pada output analog VSD fan AHU.

3. Mode otomatis, sistem berhasil beroperasi dengan schedule sesuai sequence system pada pedoman ASHRAE Guideline 132015.

4. Mode gangguan berhasil mendeteksi gangguan, menampilkan message alarm, dan mengaktifkan safety shutdown.

5. Komunikasi Modbus ke BACnet pada power meter menggunakan MBS Gateway berhasilkan menampilkan data yang sesuai pada timestamp yang sama.

6. Trend yang ditampilkan pada plant sistem AHU dapat diatur pada posisi $\mathrm{X} / \mathrm{Y}$ sesuai kebutuhan user dan dapat dilihat berdasarkan periode waktu, hari, dan bulan. Selain itu, trend log pada plant sistem AHU juga dapat disimpan atau di-export dalam format standar seperti .XML.

\section{DAFTAR PUSTAKA}

[1] W. H. Chandra, I. B. A. Swamardika, and A. A. G. M. Pemayun, Meningkatkan Penghematan Konsumsi Energi Di Hotel Langham District 8 Scbd Jakarta, $J$. Spektrum, vol. 7, no. 3, pp. 1-7, 2020.

[2] P. Mandarani and Zaini, Pengembangan Sistem Monitoring Pada Building Automation System (Bas) Berbasis Web Di Fakultas Teknik Universitas Andalas, $J$. Tek. Elektro ITP, vol. 4, no. 2, pp. 7-16, 2015.

[3] R. A. Panke, Energy Management Systems and Direct Digital Control. 2020.

[4] P. Domingues, P. Carreira, R. Vieira, and W. Kastner, Building automation systems: Concepts and technology review, Comput. Stand. Interfaces, vol. 45, pp. 1-12, 2016, doi: 10.1016/j.csi.2015.11.005.

[5] W. Wang, M. R. Brambley, W. Kim, S. Somasundaram, and A. J. Stevens, Automated point mapping for building control systems: Recent advances and future research needs, Autom. Constr., vol. 85, no. July 2017, pp. 107-123, 2018, doi: 10.1016/j.autcon.2017.09.013.

[6] ASHRAE Technical Committee, ASHRAE Handbook: Heating, Ventilating and AirConditioning Applications Inch-Pound Edition, Inch-Pound. Atlanta: ASHRAE, 2015.

[7] C. S. ASHRAE Technical Committee 9.11, ASHRAE Design Guide for Cleanrooms: Fundamentals, Systems, and Performance. Atlanta: ASHRAE Technical Committee 9.11, Clean Spaces., 2017.

[8] Kieback Peter, Manual PS4000 V4.5.0 FUNCTIONS, 1st ed. Berlin: Kieback
Peter, 2020.

[9] D. B. Kahn et al., ASHRAE Guideline 132015, Specifying Building Automation Systems. Atlanta: ASHRAE 1791, 2015.

[10] Tang, Shu, et al. " BIM assisted Building Automation System information exchange using BACnet and IFC." Automation in Construction 110. 103049. 2020. 